\title{
Postoperative analgesia in children
}

Dušica M. Simić ${ }^{1,2}$,

Ana S. Vlajković

Marija M. Stević ${ }^{1,2}$

${ }^{1}$ Medical faculty, University of Belgrade, Dr Subotića 8, Serbia

${ }^{2}$ University Children's Hospital, Tiršova 10, Belgrade, Serbia

\section{Abstract}

In many centres for pediatric surgery too many children still experience intense postoperative pain. Factors that contribute to inadequate postoperative pain control in children are: lack of the experience, inadequate use of pain scales, interpatient variability in pain perception and analgesic requirements, differences in pharmacodynamics and pharmacokinetics, age restricted drug licensing and a relative paucity of researches. The proper pain estimation scales are dependent on the child's age and their understanding of pain and of the scale. Most commonly used drugs in pediatric postoperative pain relief are opioid and nonopioid analgesics (nonsteroidal anti-inflammatory drugs, paracetamol, metamizole, ketamine, dexamethasone and Alpha-2-agonists). The use of regional anesthesia techniques is becoming increasingly popular in postoperative analgesia following pediatric surgery. Severe acute postoperative pain in children can have significant long term effects such as chronic pain. Of great importance is that acute postoperative pain in children is optimally managed from the outset.

Keywords: postoperative analgesia, children, pediatrics, pain 


\section{Introduction:}

In 1968 comment of Swafford and Allen was: 'pediatric patients seldom need relief of pain after surgery, they tolerate discomfort well', what lead to inadequate postoperative pain management in years following (1). Up to day $40 \%$ of children in postoperative settings experienced moderate or severe pain and in $75 \%$ insufficient perioperative analgesia was prescribed or applied (2). Surgical trauma causes sympathetic activation producing endocrine, metabolic, hematologic and immune reactions (3). Regardless the development of new medications and techniques, postoperative pain management in pediatric population is a great challenge an anesthesiologist (4). Specific high-risk populations or types of surgery continue to present problems for pain control $(5,6)$. Factors that contribute to unsatisfactory pain control in children are: lack of the experience, inadequate use of pain scales, interpatient variability in pain perception and analgesic requirements, differences in pharmacodynamics and pharmacokinetics, age restricted drug licensing and a relative paucity of researches (4, 7). Noncommunicative and cognitive impaired children are more vunerable for underestimation of pain (8).

Appropriate treatment of postoperative pain contributes to increased degree of patient satisfaction, shorter time of hospitalization and consequently lower hospital costs. An ineffective treatment of postoperative pain is in positive correlation with delayed wound healing and the negative development of pain perception and chronic pain in the future $(9,10)$.

\section{Postoperative pain and rules for treat it}

During the acute phase pain can have psychological and physiological adverse effects, with long-term repercussions if is not assessed, evaluated and managed in adequate way. The plasticity of the developing nervous system and immature descending modulatory pathways may predispose children with untreated acute pain to hyperalgesia and chronic pain. Chronic postsurgical pain (CPSP) is described as pain persisting 3 months postsurgery. Only few, mostly retrospective researches investigated CPSP in the childhood (11). Batoz and authors found two major risks for development of CPSP: the presence of recent pain $(<1$ month) before surgery and severe acute in the first $24 \mathrm{~h}$ postoperatively (12). The World Health Organization (WHO) guidelines for pharmacological treatments for children's pain recognize that pain in children is a public health problem of a great importance (13). These guidelines stated that the rule for treating pain is to administer analgesics 'around the clock' (ATC) rather than on an 'as required' (termed 'pro re nata' or PRN) (when pain occurs) basis. The National Institute for Health Researches (NIHR) in the UK established: "Guidelines on postoperative management of pediatric pain recommend time-contingent analgesic dosing to reduce or prevent pain before it begins. Potential benefits of this approach include the maintenance of therapeutic levels of opioids, the facilitation of routine postoperative activities (e.g., oral intake, activity, sleep), and the avoidance of delays in analgesic administration because of inaccurate parental assessment of children's pain behaviours. 
However, many clinicians and parents fear that regularly scheduled administration of analgesics may result in the administration of unnecessary and/or excessive amounts of analgesics, which may cause undesirable and potentially harmful adverse effects. As a result, children are often not given enough pain control in the post-operative period. It is necessary to assess the actual evidence to determine the benefits and/or harms of regular dosing of analgesics versus 'when needed' following surgery in children (13)."

\section{Postoperative pain assesment tools}

Comprehensive research has led to the accessibility of justified, reliable and recommended tools to measure children's pain of all ages and developmental levels (14). The discrepancy among improvements in pain assessment tools and pain management outcomes can be explained in the way the evidence for pain assessment may have failed in translation in clinical practice. In younger than 6 years, behavioral pain tools are imperative in estimation the pain: for older than 6 years the gold standard is self-reported pain. For newborns and infants fewest behavioral pain tools have good validity, but the Children and Infants Postoperative Pain Scale (CHIPPS) and EVENDOL can evaluate the pain in all infants younger than 1 year old (15). The CHIPPS has also been proved for postoperative pain estimation in age 0 to 5 years. Crying, requires increased oxygen consumption, increased vital signs, expression and sleeplessness scale (CRIES) has been verified in newborns from 32 weeks gestational age to age 6 months in intensive care units (16). The validity criteria for CRIES are weaker than with the EVENDOL or CHIPPS tools. The Faces, Legs, Activity, Cry and Consolability (FLACC) scale is credible in children age 6 months to 5 years with acute pain in heterogeneous settings (17). For postoperative pain in children age 1 to 13 years the Objective Pain Scale (OPS) is valid. The Pain Observation Scale for Young Children estimates postoperative pain in children age 1 to 4 years. The gold standard for children older than age 6 years is self-assessment by a visual-analogue scale (VAS) (18).

The Postoperative Pain Measure for Parents (PPMP) is used by parents after children return home. For the assessment of pain in sedated or unconscious child, the COMFORT Behavior scale is the most appropriate. In children with cognitive disabilities, NCCPC-PV (NonCommunicating Children Pain Checklist Postoperative Version) and r- FLACC (revised FLACC) seem valid in interpretation the pain (15).

\section{The Pain Management}

The American Pain Society recommendations established on the basic premise that optimal pain management begins in the preoperative period with evaluation of the patient and development of a plan of care modified to the individual patient and the type of surgical procedure (19). Most commonly used drugs in pediatric postoperative pain relief are opioid and nonopioid analgesics (nonsteroidal anti-inflammatory drugs, paracetamol, metamizole, dexamethasone, alpha 2 agonists and ketamine). Few clinical trials have investigated the efficacy of non-opioid analgesic interventions for ameliorate postsurgical pain control. The lack of recommended methods for multimodal analgesic administration in pediatric patients can result in an increased use of opioid medications in the 
postoperative period. Patient-controlled analgesia (PCA) is a safe and efficacious method which provides appropriate level of analgesia in children over 5 years of age (20). Multimodal therapy is supported in many circumstances, while the exact elements of multimodal care will vary depending on the patient, setting and surgical intervention. Methods of nonpharmacological pain management as distraction, music therapy and hypnosis are also described. The use of regional anesthesia for postoperative pain control has significantly increased in pediatric patients. Ultrasonography assistance in the performing of regional blocks increased the use of regional anesthesia techniques. The ESPA Pain Ladder provides guidelines for postoperative analgesia for six frequently performed surgical procedures in children (hernia inguinalis, circumcision, pyloromyotomy, adeno-tonsillectomy, appendectomy and limb fracture) (21). The actual topic in perioperative pediatric medicine is to decrease the prescription of opioids and the review of multimodal analgesia method (ie, regional anesthesia). In children with an intravenous line in place, intravenous administration is recommended; second choice is a syrup or small tablets. Suppositories and intramuscular application should not be used in non-sedated children.

\section{Preemptive Analgesia}

Preemptive analgesia is described as treatment that begins before surgery and has an idea to prevent the development of central pain sensitization. However, since its first introduction in the 1988, preemptive analgesia has provoked many controversial opinions. Fewest meta-analyses of the efficacy of preemptive analgesia on postoperative pain management have brought to conflicting conclusions (22).

\section{Nonsteroidal Anti-Inflamatory Drugs (NSAIDs)}

NSAIDs are worthy for mild to moderate postoperative pain control because surgery causes pain and inflammation. In the treatment of severe pain, NSAIDs need to be ordinated with paracetamol or opioids or in addition an adequate regional analgesic technique should be considered. They are more advantageous in preventing pain, than in the relief of established pain. The most extensively evaluated NSAIDs in children are ibuprofen, diclofenac, ketoprofen and ketorolac. There is no major difference in the analgesic action when appropriate doses of each drug are used. Severe adverse effects of NSAIDs in children are very rare. A few researches demonstrate conflicting evidence that ketorolac may increase bleeding more so than other NSAIDs. Caution in using should be in children with liver dysfunction, impaired renal function, hypovolemia or hypotension, coagulation disorders, thrombocytopenia or active bleeding. It seems that most children with mild asthma may use NSAIDs safely (23).

\section{Paracetamol}

Paracetamol is a widely accepted standard treatment for mild to moderate acute postoperative pain in children. In a combination with other analgesics, paracetamol may upgrade pain control. It has established safety profile and effectiveness, especially when compared with other antipyretic drugs. The global risk of paracetamol induced hepatotoxicity seems to be lower in children than in adults. Intravenous paracetamol, administered in a 15-minute infusion, is a fast acting analgesic drug and has more rapid onset of analgesia than paracetamol in oral form (24). 


\section{Metamizole}

It has been banned in a number of countries due to a possible risk of agranulocytosis with the use of metamizole. Knowledge about the use of metamizole in children is still deficient (25). Metamizole has analgesic, antipyretic, spasmolytic and weak anti-inflammatory properties. Evidence is lacking to support the claim that metamizole is equivalent or even superior to nonsteroid anti-inflammatory drugs in pediatric pain control. While the absolute risk of agranulocytosis in children, based on available literature, cannot be determined, case reports suggest that this risk is not insignificant, but not greater then in other drugs (25). The profile of adverse event of metamizole distinguishes from that of other NSAIDs (26).

\section{Dexamethasone}

Dexamethasone is a high potency and long acting glucocorticoid with a powerful anti-inflammatory effect. Its effectiveness in reduction of postoperative pain, nausea and vomiting has been verified in some surgical interventions in the childhood, such as tonsillectomy and orchiopexy (27). Dexamethasone has become a popular additive for regional anesthesia. Caudal and intravenous dexamethasone could provide longer duration of postoperative analgesia and reduced the incidence of postoperative vomiting with comparable adverse effects than regular caudal block (28).

\section{Alpha-2-Adrenoreceptor Agonists}

Alpha-2-adrenoreceptor agonists produce sedative and antinociceptive effects indicating that this group of substances might play an important role in the perioperative care of children (29). Dexmedetomidine, currently the most selective alpha-2-adrenoreceptor agonist with a short terminal half-life, maintains respiratory function and can be applied via different routes (e.g., intravenous, intranasal, buccal, subcutaneous, epidural). Schnabel and authors showed that similar postoperative analgesia was achieved with application of intraoperative opioid (30). Regardless diversity between trials, clonidine premedication in sufficient dose was likely to have a valuable effect on postoperative pain in children (29).

\section{Ketamine}

The use of ketamine for a long was focused on its anesthetic properties, but recently interest has focused for the management of postoperative pain (31). The main analgesic effect is effect of antagonism of N-methyl-D-aspartate (NMDA) receptors, modulating central sensory processing of pain. Ketamine can be used as a standalone analgesic drug or as an adjuvant to other analgesics.

Many studies have demonstrated notable benefits of ketamine in prevention and treatment of postoperative pain, increasing time to first analgesic request and reducing the opioid requirements (32). In order to his antihyperalgesic characteristics, it can oppose to opioid induced hyperalgesia. Ketamine also can prevent the development of opioid tolerance. High-quality, large, controlled researches are needed in order to define which procedures are acceptable for and at what dosages and frequencies it should be ordinated.

\section{Opioids}

Commonly use of opioid analgesia for postoperative pain treatment is a great controverse. 
In the management of moderate acute or chronic pain when nonopioids agents do not provide adequate analgesia, a patient will be given opioids. Up to $8.2 \%$ of adult patients who gets opioids for postoperative pain control may become opioid addicts. There is no research which evaluated this risk for pediatric population, but clinicians should decrease administration of opioids in pediatric (33). Board spectrum of side effects, which includes respiratory depression, postoperative nausea and vomiting, urinary retention, constipation and pruritus, remain a great concern in the postoperative period (34). There is a lack of established protocols for prescribing opioids in children. Codeine and tramadol as weak opioids had been usually added to nonopioid medications, but now they are no longer suggested to be used in children. Morphine is the gold standard in severe pain management. Drugs of second choice instead of morphine are oxycodone, hydrocodone and fentanyl, all with heterogeneus pharmacokinetic profiles. When rapid onset of action is desired, for example is the case with acute postoperative pain, fentanyl, alfentanil, remifentanil and sufentanil are selected. Weak and other the more potent opioids appear to bear almost equivalent risk for adverse events. Newborns and infants cannot self-report pain what makes them more predisposed to opioid caused adverse events such as respiratory depression, what tells to us that there is neccesity for a more personalized access. Opioids are usually given orally or intravenously around a clock or through patient-controlled analgesia (PCA). The superiority of this method of analgesic administration compared with continuous IV infusion or intermittent administered injections is that the patient can titrate the opioid delivery to achieve sufficient pain control.

\section{Regional Anesthesia}

Central and peripheral regional anesthesia of the surgical site can reduce the need for perioperative opioids thereby decreasing their undesirable adverse effects. Nerve blocks performed while the patient is anesthetized reduce the need for analgesics in the postoperative period. Hence, methods to provide analgesia while avoiding or reducing the need for opioids may help decrease post-operative opioid associated morbidity (35). Caudal epidural blocks are one of the most frequently used techniques in pediatric regional anesthesia with success of more than $95 \%$. Although there is not much objective evidence, large prospective databases and expert opinion have favored administering regional anesthesia in the sleeping or sedated child safely, because major neural damage has not been reported in children (36).

\section{Ambulatory Surgery}

Ambulatory surgery is a great and an increasing portion of pediatric surgical practice. Several researches point out that pain succeeding ambulatory surgery in children often is inadequately treated (37, 38). The responsibility for administration of analgesics after patients discharge from hospital lies on the parents. In a busy outpatient clinic, contacts between healthcare professionals and the family are increasingly insufficient, which consequently lead to inefficient postoperative pain control. Parents were instructed to use a fixed schedule of analgesics administration in weight appropriate doses for the first $24 \mathrm{~h}$ after surgery procedure. 


\section{Conclusion:}

Postoperative pain in pediatric population remains inadequately treated in many centers. The multimodal approach is recommended for optimal pain control in children. NSAIDs and opioids coadministration reduces postoperative opioid demand and side effects and increased pain relief. Wherever practicable, regional analgesia should be performed with a combination of systemic analgesics. Best practice proposes that opioids should not be administered alone. Continious education programs and protocols for managing postoperative pain in children will improve everyday practice. The existence of a devoted pain management team should be the standard. 


\section{REFFERENCES:}

1. Swafford L, Allen D. Pain relief in the pediatric patient. Med Clin North Am. 1968;52:131 - 136.

2. Mather L, Mackie J. The incidence of postoperative pain in children. Pain. 1983;15:271 282.

3. Karisik M, Barhanovic NG, Vulovic T, Simic D. Postoperative Pain and Stress Response: Does Child's Gender Have an Influence? Acta Clinica Croatica. 2019;(2):274.

4. Song IK, Park YH, Lee JH, Kim JT, Choi IH, Kim HS. Randomized controlled trial on preemptive analgesia for acute postoperative pain management in children. Pediatric Anesthesia. 2016:26(4):438-443.

5. Groenewald CB, Rabbitts JA, Schroeder DR, Harrison TE. Prevalence of moderate-severe pain in hospitalized children. Paediatr Anaesth. 2012;22:661 -8 .

6. Kozlowski LJ, Kost-Byerly S, Colantuoni E,etal.Pain prevalence, intensity,assessment and management in a hospitalized pediatric population. PainManag Nurs 2014; 15:22 - 35.

7. Brand K, Al-Rais A. Pain assessment in children. Anaesthesia \& Intensive Care Medicine. 2019:20 (6):314-317.

8. Manworren RC, Stinson J. Pediatric Pain Measurement, Assessment, and Evaluation. Semin Pediatr Neurol. 2016 Aug;23(3):189-200.

9. Boric K, Dosenovic S, Jelicic Kadic A, Batinic M, Cavar M, Urlic M, Puljak L. Interventions for postoperative pain in children: An overview of systematic reviews. Pediatric Anesthesia.2017:27 (9):893-904.

10. Brown R, Fortier M, Zolghadr S, Gulur P, Jenkins B, Kain Z. Postoperative Pain Management in Children of Hispanic Origin: A Descriptive Cohort Study. Anesth Analg. 2016 Feb; 122(2): 497-502.

11. Rabbitts JA, Fisher E, Rosenbloom BN, Palermo TM. Prevalence and Predictors of Chronic Postsurgical Pain in Children: A Systematic Review and Meta-Analysis. J Pain. 2017;18(6):605-614.

12. Batoz H, Semjen F, Bordes-Demolis M, Bénard A, Nouette-Gaulain K. Chronic postsurgical pain in children: prevalence and risk factors. A prospective observational study. British Journal of Anaesthesia. 2016:117(4):489-496.

13. Hobson A, Wiffen PJ, Conlon JA. As required versus fixed schedule analgesic administration for postoperative pain in children. Cochrane Database Syst Rev. 2015;2015(2):CD011404.

14. Fernandes AM, De Campos C, Batalha L, Perdigão A, Jacob E. Pain assessment using the adolescent pediatric pain tool: a systematic review. Pain Res Manag. 2014;19(4):212-218.

15. Beltramini A, Milojevic K, Pateron D. Pain Assessment in Newborns, Infants, and Children. Pediatr Ann. 2017 Oct 1;46(10):e387-e395.

16. Krechel SW, Bildner J. CRIES: a new neonatal postoperative pain measurement score. Initial testing of validity and reliability. Paediatr Anaesth. 1995;5 (1):53-61.

17. Johansson M, Kokinsky E. The COMFORT behavioural scale and the modified FLACC scale in paediatric intensive care. Nurs Crit Care. 2009 MayJun;14(3):122-30.

18. Bringuier S, Dadure C, Raux O, Dubois A, Picot MC, Capdevila X. The perioperative validity of the visual analog anxiety scale in children: a discriminant and useful instrument in routine clinical practice to optimize postoperative pain management. Anesth Analg. 2009 Sep;109(3):737-44.

19. Chou R, Gordon DB, de Leon-Casasola OA, Rosenberg JM, Bickler S, Brennan T et al. Management of Postoperative Pain: A Clinical Practice Guideline From the American Pain Society, the American Society of Regional Anesthesia and Pain Medicine, and the American Society of Anesthesiologists' Committee on Regional Anesthesia, Executive Committee, and Administrative Council. J Pain. 2016 Feb;17(2):131 57.

20. Simić D, Budić I, Simić I, Stanković Z, Milenović M, Stević M. Patient-controlled analgesia for infants and children. Pain Medicine Journal. 2017;2(3):19-24

21. Vittinghoff M, Lönnqvist PA, Mossetti V, Heschl S, Simic D, Colovic Vet al. Postoperative pain management in children: Guidance from the pain committee of the European Society for Paediatric Anaesthesiology (ESPA Pain 
Management Ladder Initiative). Paediatr Anaesth. 2018 Jun;28(6):493-506

22. Sener M. Preemptive analgesia for acute postoperative pain management in children. Pediatric Anesthesia. 2016:26(8):856-856.

23. Michelet D, Andreu-Gallien J, Bensalah T, Hilly J,Wood C, Nivoche Y, Dahmani S. A Meta-Analysis of the Use of Nonsteroidal Antiinflammatory Drugs for Pediatric Postoperative Pain. Anesthesia \& Analgesia. 2012:114(2):393-406.

24. Remy C, Marret E, Bonnet F. State of the art of paracetamol in acute pain therapy. Current Opinion in Anaesthesiology.2006:19(5):562-565.

25. De Leeuw TG, Dirckx M, Gonzalez Candel A, Scoones GP, Huygen FJPM, de Wildt SN. The use of dipyrone (metamizol) as an analgesic in children: What is the evidence? A review. Pediatric Anesthesia. 2017:27(12):1193-1201.

26. Konijnenbelt-Peters J, van der Heijden C, Ekhart C, Bos J, Bruhn J, Kramers C. Metamizole (Dipyrone) as an Alternative Agent in Postoperative Analgesia in Patients with Contraindications for Nonsteroidal Anti-Inflammatory Drugs. Pain Practice. 2016:17(3): 402-408.

27. Zhou G, Ma L, Jing J, Jiang H. A meta-analysis of dexamethasone for pain management in patients with total knee arthroplasty. Medicine (Baltimore). 2018;97(35):e11753.

28. Zhu C, Zhang S, Gu Z, Tong Y, Wei R. Caudal and intravenous dexamethasone as an adjuvant to pediatric caudal block: A systematic review and meta -analysis. Pediatric Anesthesia.2018:28(3):195-203.

29.J oseph A. Giovannitti, Jr, Sean M. Thoms, James J. Crawford. Alpha-2 Adrenergic Receptor Agonists: A Review of Current Clinical Applications. Anesth Prog. 2015 Spring; 62(1): 31-38.

30. Schnabel A, Reichl SU, Poepping DM, Kranke P, Pogatzki-Zahn EM, Zahn PK. Efficacy and safety of intraoperative dexmedetomidine for acute postoperative pain in children: a meta-analysis of randomized controlled trials. Pediatric Anesthesia. 2012:23(2):170-179.

31. Radvansky BM, Shah K, Parikh A, Sifonios AN, Le V, Eloy JD. Role of ketamine in acute postoperative pain management: a narrative review. Biomed Res Int. 2015;2015:749837.
32. Dahmani S, Michelet D, Abback PS, Wood C, Brasher C, Nivoche Y, Mantz J. Ketamine for perioperative pain management in children: a metaanalysis of published studies. Paediatr Anaesth. 2011 Jun;21(6):636-52.

33. Zhu A, Benzon HA, Anderson TA. Evidence for the Efficacy of Systemic Opioid-Sparing Analgesics in Pediatric Surgical Populations. Anesthesia \& Analgesia. 2017:125(5);1569-1587.

34. Mark Edmund Rose. Are Prescription Opioids Driving the Opioid Crisis? Assumptions vs Facts. Pain Med. 2018 Apr; 19(4): 793-807.

35. Suresh, S, Barcelona SL, Young NM, Seligman I, Heffner CL, Coté, C. J. Postoperative Pain Relief in Children Undergoing Tympanomastoid Surgery: Is a Regional Block Better than Opioids? Anesthesia \& Analgesia. 2002:94(4):859-862.

36. Weinstein EJ, Levene JL, Cohen MS, et al Local anaesthetics and regional anaesthesia versus conventional analgesia for preventing persistent postoperative pain in adults and children. Cochrane Database Syst Rev. 2018;4(4):CD007105.

37. Shum S, Lim J, Page T et al. An audit of pain management following pediatric day surgery at British Columbia Children's Hospital. Pain Res Manag. 2012;17:328-334.

38. Finley GA, McGrath PJ, Forward SP et al. Parents' management of children's pain following 'minor' surgery. Pain. 1996;64:83-87.

$\begin{array}{llll}\text { Primljen } & * & \text { Received } & 16.1 .2020 . \\ \text { Prihvaćen } & * & \text { Accepted } & 20.1 .2020 .\end{array}$


Pregledni rad/Review doi:10.5937/abc2001001S

Postoperativna analgezija kod dece

ABC časopis urgentne medicine 2020;20:(1):1-10

\section{Postoperativna analgezija kod dece}

Dušica M. Simić ${ }^{1,2}$,

Ana S. Vlajković ${ }^{2}$,

Marija M. Stević ${ }^{1,2}$

${ }^{1}$ Medicinski fakultet, univerzitet u Beogradu, Dr Subotića 8, Serbia

${ }^{2}$ University Children's Hospital, Tiršova 10, Belgrade, Serbia

\section{Sažetak}

U mnogim centrima za dečju hirurgiju još uvek mnoga deca osete jak postoperativni bol. Faktori koji doprinose neakvatnom zbrinjavanju postoperativnog bola kod dece su: nedostatak iskustva, neadekvatna upotreba skala za procenu bola, individualna osetljivost na bol i potreba za analgeticima, razlike u farmakodinamici i farmakokinetici, starosno zavisno licenciranje lekova i relativni nedostatak odgovarajućih studija. Skale za procenu bola su zavisne od uzrasta deteta, njihovog razumevanja bola i skala. Najčešće korišćeni lekovi u zbrinjavanju postoperativnog bola kod dece su opioidni i neopioidni analgetici (nesteroidni antiinflamatorni lekovi, paracetamol, metamizol, dexamethasone Alfa-2-agonisti i ketamine). Izvođenje tehnika regionalne anestezije postaje sve popularnije u cilju dobre postoperativne analgezije u dečijoj hirurgiji. Jak akutni postoperativni bol kod dece može da ima ozbiljne dugoročne posledice kao što je hronični bol. Od velike je važnosti da se akutni postoperativni bol leči od samog početka.

Ključne reči: postoperativna analgezija, deca, pedijatrija, bol 